\title{
A persistente primazia política da corporação militar
}

\section{The persistent political primacy of the military corporation}

\section{MILITARES, PODER E SOCIEDADE NO BRASIL, ALGUNS CLÁSSICOS DA LITERATURA}

A exemplo de qualquer objeto de estudo que interpela o poder ou com ele interage, a necessidade de entendimento das Forças Armadas como objeto delimitado da ciência política se impôs quando se tornaram atores relevantes para a dinâmica política e social do país, quer por seu papel simbólico ou prático, quer por valores patrióticos, republicanos ou morais.

Não mencionaremos a literatura e relatos sobre guerras, descrições, quase sempre apologéticas, de batalhas e confrontos, ou biografias de militares considerados grandes figuras em seu ofício. A guerra do Paraguai, em especial, suscitou alguns desses trabalhos, sendo talvez o mais conhecido A retirada da Laguna - episódio da Guerra do Paraguai, do Visconde de Taunay, publicado pela primeira vez, em francês, em 1871.

A proclamação da República não teria sido feita com tanta eficácia não fora a ação dos jovens oficiais do Exército e aqui o objeto de estudo despontava mais marcadamente nas suas conexões com a política. $\mathrm{O}$ golpe de 1889, contudo, não produziu um governo militar de longo prazo. Pelo contrário, quatro anos depois, as oligarquias paulistas passaram a liderar formalmente o processo político em aliança com outras oligarquias locais. Nos anos 1920, volta a haver um questionamento interno às Forças Armadas, sério e intenso, sobre qual deveria ser o seu papel na política. A crítica de parte da jovem oficialidade aos governos das elites oligárquicas da época toma ares de rebelião. O tenentismo surgia como fenômeno político e até hoje é tema de reflexão intelectual, pois marca de forma indelével uma intervenção militar na política que iria avançar, em diferentes momentos e com objetivos distintos, até o golpe de 1964.

Maria Celina Soares D’Araujo - Professora de graduação e pós-graduação na Pontifícia Universidade Católica do Rio de Janeiro. Doutora em Ciência Política, Pesquisadora 1C do CNPq, mariacelina@daraujo.net. 
Não por acaso, os estudos mais elaborados sobre os militares vieram depois da Revolução de 1930, na qual os tenentes tiveram papel crucial e foram, junto com alguns generais, figuras de proa do Governo Getúlio Vargas então iniciado.

Em 1933, o engenheiro Virgínio Santa Rosa, um republicano nacionalista, antioligarca e admirador do fascismo, publicou uma obra seminal intitulada Os sentidos do tenentismo. Para o autor, a intervenção dos tenentes representava a emergência da classe média na política, num protesto necessário e bem-sucedido contra as oligarquias. Os tenentes teriam extração social nessa classe emergente e dela seriam porta-vozes e protagonistas para a remoção das oligarquias do poder. O país passava, segundo ele, por uma reconfiguração em sua estrutura de classes e, por meio dos militares, a classe média desalojaria as velhas elites a quem haviam servido durante séculos. Ou seja, as mudanças na estrutura de classes na sociedade brasileira foram de tal monta que a nova classe média em ascensão impactava de tal forma as Forças Armadas a ponto de agirem como suas representantes. $\mathrm{O}$ pacto político das elites com os quartéis estaria desfeito. Um novo contrato social estava sendo desenhado entre os quartéis e a sociedade.

A história e estudos posteriores minuciosos mostraram que a tese de Virgínio Santa Rosa não estaria adequada para explicar as ações políticas dos militares em seus vínculos com a estrutura de classes na sociedade brasileira. As oligarquias, com suas diferentes facções, continuaram fortes e aliadas no governo, mantiveram e continuam mantendo protagonismo acentuado nas estruturas de poder.

De toda forma, o vínculo das Forças Armadas com classes sociais passou a ser uma chave interpretativa que até hoje tem seus seguidores. Esta associação só é possível porque parte da teoria social adotou o conceito marxista de classes sociais como categoria analítica privilegiada para explicar as relações de poder em uma sociedade. Poder e luta de classes seriam dois lados da mesma moeda. Como os militares nas sociedades modernas eram, e são, o braço armado dos estados nacionais, ter o controle sobre a força bruta era vital para a configuração do sistema político. As classes médias, em 1930, por meio das Forças Armadas, teriam chegado ao poder pela força e não pelo voto.

Esse contorno classista para entender a ação das Forças Armadas será acionado em várias ocasiões e de diferentes maneiras. A literatura sobre o golpe de 1964, muitas vezes, enfatiza a conexão dos militares golpistas com as classes empresariais, vinculadas ao capital nacional e estrangeiro (burguesia). O livro mais expressivo a esse respeito é o de Renê Dreifuss, 1964, a conquista do Estado, publicado em 1981. Desta feita, a corporação não representa a classe média majoritária, mas sim uma reduzida elite que 
concentrava dinheiro e poder. Mais uma vez, vemos que as Forças Armadas agem a serviço de interesses de classe. São forças pretorianas que atuam para proteger aqueles que lhe asseguram prestígio, orçamento e carreira.

Aolado desta vertente classista, outra ganhou espaço depois da Revolução de 1930. Estamos falando daquela que vincula as Forças Armadas ao surgimento da nacionalidade e do Estado, visão ainda corrente, especialmente entre os próprios militares. Obra exemplar e inaugural nessa direção vem de Gustavo Barroso. Sua História Militar do Brasil, publicada em 1935, faz a descrição das vestimentas e armamentos militares ao longo da colônia e do império, bem como da participação dos militares brasileiros em conflitos regionais. Neste, e em outros trabalhos, o autor retrata os militares como agentes formadores da nacionalidade. Confundem-se com a origem e a história da pátria, são parte fundadora e indissociável de um todo chamado Estado Nacional. Esta é, aliás, uma maneira ainda usual de lidar com a instituição, especialmente quando se olham os documentos oficiais.

Ao lado da vinculação teórica feita entre Forças Armadas e classes sociais e entre Forças Armadas e construção nacional, temos outra maneira de focar o tema: estabelecer vínculos dos militares com ideologias políticas. Para autores como Santos (1963) e Sodré (2011), os militares, até 1964, teriam um componente eminentemente democrático, estiveram ao lado do povo e das causas nacionais.

O clássico Quem dará o golpe no Brasil (Santos 1962) foi entendido por muitos como a principal obra de previsão na política brasileira, mesmo que renegada por seu autor em anos posteriores e mesmo que seus acertos sejam poucos. O golpe em marcha nos anos 1960, segundo Santos, tiraria João Goulart, um governo burguês, do poder dando lugar a outro governo forte, mas igualmente civil. O golpe era um recurso que a minoria dominante tinha para assegurar seus privilégios por novos meios, isto é, via "governo forte". Não estava nessa análise a possibilidade de uma ditadura militar por duas razões: o contexto internacional do sistema capitalista não recomendaria esse tipo de governo e, embora houvessem militares golpistas, "as Forças Armadas no Brasil não constituem uma casta, não possuindo assim, nesse particular, a condição que favoreça um modo de agir coeso, com unidade de orientação e de comando, em relação às demais forças sociais" (Santos 1962, 25). As Forças Armadas, por não se identificarem com nenhuma classe dominante, ficariam alheias ao poder, ao lado do povo e da soberania nacional.

O general Nelson Werneck Sodré, intelectual marxista com grande proliferação de trabalhos sobre diversas áreas de conhecimento, publicou sua História militar do Brasil em 1965. Nela faz o relato da longa trajetória do Exército brasileiro, até 1964, mostrando sua vocação para defender os 
interesses do povo e do nacionalismo. Isso muda nos anos 1960 em decorrência da grande reação anticomunista, de recorte imperialista, e da pouca habilidade de João Goulart, para, segundo ele, manejar a questão militar e as divisões dentro da esquerda.

Não são poucos, contudo, os que vinculam Forças Armadas a autoritarismo, notadamente depois do golpe de 1964. Até então era mais comum entender as Forças Armadas como um epifenômeno da luta de classes e se a análise tendesse para associá-las com as classes populares, logo se concluía que eram democráticas. Assim, depois de instaurada a ditadura militar e, portanto, a posteriori, estabilizou-se na academia brasileira a associação entre Forças Armadas e autoritarismo. Esta passaria a ser sua marca de origem, o principal componente definidor de sua ideologia política. Desta forma, o tema da ideologia política tornou-se nexo obrigatório para tratar do assunto.

Com o golpe de 1964 os estudos sobre as relações dos militares com a política e com a sociedade passam a ter como empiria privilegiada aquele fato histórico e a partir dele grande parte das visões sobre a instituição e seu passado foram refeitas.

A intervenção militar em si não era uma surpresa. Seria apenas mais uma das várias ações e reações dos militares no campo da política. Desde os anos 1920, mas especialmente depois de 1930, a presença das Forças Armadas em momentos de tensão política foi uma constante. Houve também momentos que um grupo isolado e minoritário atuou militarmente, de modo próprio, contra o governo. Este foi o caso dos levantes de Jacareacanga e Aragarças, com a participação apenas da Aeronáutica. Reagiam ao que denominavam a comunização do governo Juscelino Kubitschek (1956-1961) e pediam sua deposição. Em diversas ocasiões manifestaram-se contra ações do governo (aumento do salário mínimo em 1954, por exemplo) e em outros atenderam a apelos de setores políticos, como na interdição do mandato de Café Filho na Presidência da República. As intervenções eram pontuais e o governo civil era restaurado. ${ }^{1}$

Mil novecentos e sessenta e quatro foi um acontecimento inédito de tal magnitude que obrigou a rever a maneira de pensar o objeto de estudo em várias dimensões. O golpe redundara, a posteriori, em um governo militar de recorte autoritário cujo autoritarismo se acentuava rapidamente. As análises passam a incorporar outros quesitos sociológicos como o das organizações. Não se tratava mais de fazer análises macrossociológicas das relações dos militares com as estruturas sociais mas de entender um fenômeno político em particular para daí derivar algumas lições. Também não se tratava de relevar as conexões dos militares com o "povo" e as "causas nacionais”. O eixo de análise muda para as relações das Forças Armadas 
com a política. Passou-se a tratar a política como uma esfera autônoma de conhecimento, passível de ser conhecida com métodos próprios sem ter que ser subsumida ou reduzida a um epifenômeno. As Forças Armadas passam a ser estudadas como atores políticos e como instituição que em termos analíticos recebem tratamento individualizado, postura que passa a ser adotada também por corajosos historiadores que aceitaram o risco de pensar o tempo presente.

Algumas obras são paradigmáticas para entender este salto qualitativo nos estudos. Em 1969 o cientista político Alfred Stepan defendeu sua famosa tese de doutorado na Universidade Columbia, traduzida no Brasil, em 1975, com o título de Os militares na política: as mudanças de padrões na vida brasileira. Para ele a instituição militar devia ser pensada como um "subsistema" dentro do sistema político e que a ele reagiria quando ocorressem mudanças. O trabalho tornou-se conhecido pelas fontes de pesquisa usadas, mas principalmente por ter introduzido o conceito de "padrão moderador”. Isto porque, no seu modo de ver, até 1964, as Forças Armadas eram acionadas para depor um governo e transferi-lo a outro grupo de políticos civis. O golpe de 1964 muda esse “padrão” e isso por várias razões, entre elas, a influência da Doutrina de Segurança Nacional estudada e disseminada pela Escola Superior de Guerra (ESG), criada em 1949. Essa doutrina teria sido propulsora de uma concepção do papel político dos militares como responsáveis pela política no desenvolvimento nacional. Além do mais, as tentativas de quebra de disciplina nos quartéis no Governo João Goulart e o temor do comunismo, entre outros fatores, levaram as Forças Armadas a deixar de lado o "padrão moderador", de modo a controlar diretamente o poder extirpando certos atores políticos por eles considerados disruptivos. (Stepan 1975, 124).

Em 1976 Edmundo Coelho lança sua polêmica obra Em busca de identidade, investindo contra o que considera ser o mito da função moderadora proclamada por Stepan. Em detalhada análise da ação militar durante a República, o autor mostra como a instituição foi audaz na defesa de seus interesses corporativos e como se converteu em força política na sociedade brasileira. Seu ponto de vista metodológico é o de que as Forças Armadas devem ser estudadas como uma organização, que como tal, tem interesses próprios e não se confundem com interesses de terceiros, venham eles do Estado ou da sociedade.

Finalmente, outro autor fundamental neste debate é o historiador José Murilo de Carvalho que, em 1977, publicou pela primeira vez "As Forças Armadas na Primeira República: o Poder Desestabilizador" (Carvalho, 1978). Este e outros estudos posteriores, reunidos no livro Forças Armadas e política no Brasil, de 2005, tornaram-se clássicos e denotam uma nova 
maneira de pensar o papel dos militares na política. Sem deixar de lado os vínculos enraizados das Forças Armadas com a sociedade, Murilo também privilegia o foco organizacional. Por essa via também se opõe à tese do "padrão moderador" e fornece evidências abundantes de que os militares sempre foram um poder desestabilizador das relações de poder desde o início da República. Uma evidência desse cunho organizativo e institucional é o de que a ditadura militar não cultuou nenhum general no poder, houve rodízio de presidentes, sinalizando o aspecto corporativo da ditadura.

Fizemos até aqui uma breve perspectiva das análises sobre as relações civil-militares no Brasil, por meio de algumas obras consagradas. Como se vê, a tendência dominante é pensar as Forças Armadas como atores políticos imprescindíveis para o entendimento de nossa história republicana, quer como fundadores da nacionalidade, quer como agentes a serviço do povo ou de interesses dominantes, ou ainda como atores movidos por orientação própria. Em todos os casos, nota-se que a relação com a sociedade supõe um status superior, uma posição privilegiada. As relações civil-militares na república teriam sido assimétricas. A visão de que há uma preeminência militar passou a ser corrente.

\section{AUTONOMIA NAS RELAÇÕES CIVIL-MILITARES: O CASO DA JUSTIÇA MILITAR}

Partindo da concordância de que há, entre os militares e a sociedade, uma noção de precedência das Forças Armadas sobre os demais atores sociais, vamos tomar como exemplo o caso da justiça militar e a forma como ela se organiza no país.

Em todo o mundo a ideia de reforma nesse ramo de justiça vem passando por um intenso debate e vários fatores contribuíram para isso. Os crimes de guerra na antiga Iugoslávia, em Ruanda, e depois, no Iraque, entre outros, suscitaram a necessidade de se discutir com mais afinco os flagrantes delitos praticados por militares contra leis criminais nacionais e internacionais. Além do mais, as intensas mudanças tecnológicas, o acesso das mulheres e dos homossexuais às Forças Armadas, em diversos países, trouxeram novas reflexões sobre os limites da ação repressiva entre as pessoas de uniforme e destas para com a sociedade. Mais recentemente as ações contra os atentados terroristas, especialmente a partir do atentado das Torres Gêmeas, em Nova Iorque, em setembro de 2011, e contra o Estado Islâmico, bem como a polêmica da prisão de Guantánamo, adensaram o debate.

Ademais, fatores internos às Forças Armadas também forjaram a demanda por reformas. Entre eles, as mudanças tecnológicas, o aumento do 
número de civis empregados pelas instituições militares, a participação em operações de paz, o envolvimento em guerras não declaradas e na proteção contra ataques terroristas. Todas essas mudanças internas à corporação, ao lado das mudanças quanto aos temas de gênero e de assédio moral e sexual, exigiram um sistema mais flexível para lidar com disciplina e administrar a justiça militar dentro do âmbito judicial de cada país (Kremmydiotis 2016, 313).

Uma das mais importantes colaborações sobre a reforma da justiça militar e seus desafios no século XXI é o livro organizado por Duxbury e Groves (2016). A obra reúne um conjunto de trabalhos sobre diversos países e diferentes temáticas referenciadas a esse campo da justiça em quase todos os continentes. Na América Latina, segundo Rial (2010a), devido às guerras coloniais, as Forças Armadas precedem a existência de estados independentes e têm se concebido como as principais fundadoras dos novos países ali formados. Nesse contexto, a justiça militar foi observada como um instrumento imprescindível para garantir a disciplina e a obediência e entendida como uma forma de evidenciar a autoridade e a legitimidade da cadeia de comando. Da mesma forma que se criou uma justiça específica para os militares, esses novos países também fundaram sistemas de saúde, previdência, ensino, lazer, que, no conjunto, demonstravam o histórico de autonomia em relação à sociedade.

Nesse continente, o papel da justiça militar, especialmente na segunda metade do século XX, foi além dos temas corporativos. No Peru, por exemplo, nos anos 1980 e 1990, foi usado para defender militares acusados de abusos humanos e financeiros no combate ao terrorismo e também para julgar, às vezes sumariamente, simpatizantes da guerrilha. Durante a ditadura brasileira a justiça militar atuou como justiça corporativa seguindo seu papel tradicional, como justiça política do governo julgando os acusados de conspirar contra a segurança nacional e, como justiça política intracorporação para julgar aqueles militares suspeitos de atividade política contrária ao regime (Garcia 2016). Nesse mesmo período, a variedade de usos da justiça militar foi uma constante em quase todos os países da América Latina (Rial 2010a).

O sistema de justiça militar na América Latina pode ser definido por duas características: de um lado, códigos disciplinares, criminais, normas e leis aplicáveis aos militares; e, de outro, um amplo corpo de juízes, procuradores, advogados e técnicos responsáveis pelo cumprimento desse aparato jurídico. Ao mesmo tempo, há na região dois subsistemas: um penal para crimes militares e um administrativo para infrações disciplinares. ${ }^{2}$

Os países da América Latina têm tido iniciativas para rever seu arcabouço de justiça militar, quer por meio de iniciativa legislativa (México e 
Chile), quer por iniciativa interna ao ministério da Defesa (Chile e Uruguai) ou ainda mediante reformas constitucionais como Nicarágua e Bolívia (Garcia 2016, 217). Em todos os casos, os fatores políticos são impactantes e o debate é ainda incipiente se comparado com a Europa. No caso do Brasil, o assunto está há duas décadas paralisado no Congresso Nacional.

Apesar de tudo e com lentidão, a região desperta para o debate das reformas, embora com resultados tacanhos. Os temas considerados levam em conta, basicamente, três aspectos: 1) adequação dos códigos aos novos contextos internacionais e de democracia interna; 2) eliminação da justiça militar submetendo crimes e infrações antes a ela referidos para a justiça comum; 3) restrições para que cortes militares julguem civis.

Convém lembrar que a Justiça Militar no Brasil julga crimes militares e não infrações ou delitos de caráter disciplinar e administrativo. Nesses casos aplica-se a "justiça do comandante", ou seja, o superior na cadeia de comando decide a penalidade a ser aplicada ao militar considerado infrator. $\mathrm{O}$ acusado não tem direito a habeas corpus e caso se julgue injustiçado com a penalidade recebida, só poderá recorrer à justiça comum. Neste caso, o militar terá que enfrentar o mesmo processo moroso a que são submetidos todos os demais brasileiros. Ou seja, aqui, não se aplica o princípio de que a justiça militar deve ser rápida e ágil. O tópico em pauta é, aliás, o nó górdio que vem impedindo a reforma da Justiça Militar no Brasil. É também o principal responsável pelo sentimento de injustiça dentro dos quartéis (Arruda 2007).

Desde o final do século XIX, justiça militar e situação política do país estiveram fortemente imbricadas e isso se acentua com a proclamação da República. As crises da República por sua vez, terão forte impacto nas instituições militares e em seus aparatos jurídicos. O governo provisório de 1931 continuou delegando às Forças Armadas o julgamento de civis e militares que atentassem contra a ordem pública. A Carta de 1934 traz a justiça militar para o âmbito do Poder Judiciário e retira-lhe a função de controle e revisão de atos disciplinares e administrativos. A nova Constituição mantinha, contudo, a regra que vinha do Império permitindo o julgamento de civis por crimes considerados militares, o que permanece até os dias atuais.

A legislação de exceção depois de 1964 expande o poder desse tribunal, atribuindo-lhe a prerrogativa de julgar crimes políticos, assim como ocorrera no Império e na República até 1937. O Tribunal, que contava com 11 ministros, volta a ter 15 , número que permanece hoje, em tempos de democracia e de paz. A Constituição democrática de 1988 em nada alterou o ordenamento jurídico da justiça militar. Manteve-se a estrutura e as funções da ditadura com exceção dos julgamentos de crimes contra a segurança nacional que saíram de sua alçada. As Forças Armadas deixaram, 
pela primeira vez, de ser responsáveis pelo cumprimento da Constituição, mas ganharam novas funções com o artigo que dispõe sobre a "garantia da lei e da ordem".

No período pós ditadura, a reforma da Justiça Militar veio à tona várias vezes sempre sem sucesso. A reforma do Judiciário ocorrida com a Emenda Constitucional 45 de dezembro de 2004, não a afetou. Havia ali propostas para diminuir o número de ministros e para transferir ao STM a revisão e o controle dos processos de caráter administrativo, assim como ocorrera desde o Império até a Constituição de 1934 (Souza e Silva 2016).

O que está em jogo, ainda em 2016, é o artigo 124 da Constituição de 1988, que diz: “À Justiça Militar compete processar e julgar os crimes militares definidos em lei”, ou seja, pelo Código Penal Militar de 1969, período mais grave da ditadura. Segundo a proposta em andamento, o artigo passaria a ter a seguinte redação: “À Justiça Militar compete processar e julgar os crimes militares definidos em lei, bem como exercer o controle jurisdicional sobre as punições disciplinares aplicadas aos membros das Forças Armadas” (grifos nossos). A PEC também sugere a diminuição do número de juízes de 15 para 11 .

Em entrevistas realizadas por nós com vários ministros e ex-ministros do STM ficou claro que o tema é controverso e divide opiniões dentro do Tribunal. Os argumentos contra e a favor evocam questões delicadas tanto para as Forças Armadas. Uma delas é o quanto o papel do Superior Tribunal Militar na área disciplinar poderia colidir com a chamada "justiça do comandante” e revelar-se fator contrário à coesão militar na medida em que ministros iriam apreciar decisões de seus pares militares na caserna. Outro aspecto diz respeito ao aumento de trabalho que isso representaria para o Tribunal. Para uns, essa nova atribuição daria mais legitimidade à existência do STM, para outros, o desviaria de suas funções. Há também os que defendem mais espaços e condições de acesso à Justiça para todos os integrantes da corporação. ${ }^{3}$ A divergência entre os ministros e altas patentes militares paralisam o assunto no Congresso que, em seu conjunto, continua incapaz de votar qualquer assunto que contrarie os interesses castrenses.

O STM atualmente tem 15 ministros para uma clientela de cerca de 660 mil pessoas, ${ }^{4}$ membros das Forças Armadas, da ativa, reserva, reformados e pensionistas. O Supremo Tribunal Federal, a mais alta corte do país, por sua vez, conta com 11 ministros para uma clientela potencial de cerca de 210 milhões de brasileiros, além da guarda da Constituição. Por decisão do STF, a prerrogativa de julgar civis em acordo com o que dispõe o Código Penal Militar, foi reafirmada em 2013.

De julho de 2015 a agosto de 2016, segundo o Boletim Estatístico de Pessoal do Ministério do Planejamento, o STM teve um gasto 375,4 mi- 
lhões de reais com pessoal. Nesse mesmo período, segundo a mesma fonte oficial, o total de gastos do STF foi de 371,1 milhões de reais.

Pesquisa do Centro de Estudos Judiciários da Justiça Militar, de 2013, mostra que em 2012 a justiça militar havia julgado 1.777 crimes militares. Destes, $33,6 \%$ diziam respeito a deserção de conscritos; $11 \%$ a posse ou uso de drogas ilícitas; 7,48\% a furto; e, $6,1 \%$ a estelionato. A pesquisa ainda mostra que posse ou uso de drogas ilícitas é o crime que mais cresceu entre 2008 e 2012, passando de 5\% para 11\% dos casos (STM 2013).

Ou seja, quase $60 \%$ dos trabalhos de nosso Tribunal Militar, um tribunal permanente em tempo de paz, dizem respeito a crimes tipicamente juvenis ou a crimes correntes na sociedade em geral. Por isso, merece reflexão a necessidade de um tribunal tão caro para o contribuinte em um país com tantas carências sociais e com sistema de justiça ainda tão precário para o cidadão comum. Além do mais, trata-se de uma Corte que não garante o pleno direito de defesa a todo o seu público alvo. A "justiça do comandante" permanece como um indício de prerrogativa medieval o que hoje, à luz de todo o debate sobre direitos de defesa e direitos humanos, soa anacrônico.

As Forças Armadas, apesar de terem uma corte corporativa, junto com outros funcionários públicos, representam 20\% das demandas no Superior Tribunal de Justiça e no STF. Ou seja, têm acesso a dois ramos da Justiça. Têm uma justiça corporativa para crimes militares e, nos recursos disciplinares, competem com o cidadão comum em cortes civis cuja taxa de retenção vai de $50 \%$ a $90 \% .{ }^{5}$ Em suma, no que toca ao tema justiça militar, o Brasil está na contramão da história.

Este é um dos exemplos da capacidade das Forças Armadas em preservar seus interesses institucionais mesmo que numa posição frontalmente contrária aos movimentos e ações internacionais, para diminuir o poder dos tribunais militares, proibir sua prerrogativa de julgar civis ou mesmo para extinguir esse ramo da justiça. De outra parte, demonstra a incapacidade do poder civil representado no Legislativo e até mesmo no Judiciário, em contrariar os interesses da corporação. No caso aqui examinado estamos falando na manutenção de um despropósito em tamanho, funções e custos. Um contrassenso que só faz sentido se entendermos as posições de autonomia institucional que os militares continuam mantendo mesmo em tempos de paz e de estabilidade democrática.

\section{REFERÊNCIAS}

Arruda, J. R. 2007. O uso político das Forças Armadas. Rio de Janeiro: Maud.

Barroso, G. 2000. História militar do Brasil. Rio de Janeiro: Biblioteca do Exército. 
Bermeo Lara, D., Castañeda García, I., Castro, G. F. 2010. Radiografía del sistema de justicia militar en América Latina. In: Rial, J. (Org.). La justicia militar: entre la reforma y la permanencia. Buenos Aires: RESDAL.

Brasil. Ministério de Planejamento, Desenvolvimento e Gestão. Boletim Estatístico de Pessoal, agosto de 2016. Disponível em: <http://www.planejamento.gov.br/ secretarias/upload/Arquivos/servidor/publicacoes/boletim_estatistico_pessoal/2016/161007_bol244_ago2016-parte_i.pdf>. Acesso em: novembro de 2016.

Carvalho, J. M. 2005. Forças Armadas e política no Brasil. Rio de Janeiro: Zahar.

Carvalho, J. M. 1978. "As Forças Armadas na Primeira República: o Poder Desestabilizador” In: Fausto, B. (Org.). História Geral da Civilização Brasileira. O Brasil Republicano. Tomo III, Vol. 2. São Paulo: Difel.

Castro, G. F., Bermeo Lara, D. 2008. Proyecto de Investigación "Justicia Militar, Códigos Disciplinarios y Reglamentos Generales Internos” Informe Final. Buenos Aires: RESDAL.

CNJ. Conselho Nacional de Justiça. Relatório de 2011 . Disponível em: <http://www. cnj.jus.br/noticias/cnj/58238-relatorio-de-atividades-em-2011-esta-disponivel>. Acesso em: set. 2016.

Coelho, E. 1976. Em busca de identidade: o Exército e a política na sociedade brasileira. Rio de Janeiro: Forense.

CPDOC/ FGV. Dossiê Justiça Militar. Disponível em: < http://cpdoc.fgv.br/justicamilitar>. Acesso em: set. 2016.

Dreifuss, R. 1981. 1964: a conquista do Estado. Petrópolis: Vozes.

Duxbury A. e Groves M. (orgs.). (2016) Military Justice in Modern age. University of Melbourne, Monash University, Victoria. Cambridge University Press.

Garcia, I. C. Military Justice in Latin America: a comparative analysis. 2016. In Duxbury A. e Groves M (orgs.). 2016 Military Justice in Modern age. University of Melbourne, Monash University, Victoria. Cambridge University Press.

Kremmydiotis, P.2016 The influence of human rights law on the reform of military justice. In: Duxbury e Groves.

Martins Filho, J. R. (2003). Forças Armadas e política, 1945-1964: a ante-sala do golpe. In: Delgado, Lucilia e Ferreira, Jorge (orgs). O Brasil republicano. O tempo da experiência democrática. Rio de Janeiro: Civilização Brasileira 
Rial, J. (Org.). 2010 La justicia militar: entre la reforma y la permanencia. Buenos Aires: RESDAL.

Rial, J. 2010a. Un proceso histórico de larga data: la justicia militar como regulación de una institución total. In Rial, Juan (org.). La justicia militar: entre la reforma y la permanência. Buenos Aires: RESDAL.

Rosa, V. S. 1976. Os sentidos do tenentismo. São Paulo: Alfa Omega.

Santos, W. G. dos. 1963. Quem dará o golpe do Brasil. Rio de Janeiro: Civilização Brasileira.

Sodré, N. W. 2011. História Militar do Brasil. São Paulo: Expressão Popular.

Souza, A. B., Silva, A. M. D. da. 2016. Organização da Justiça Militar no Brasil: Império e República. Estudos Históricos, 29 (58), 361-380.

Stepan, A. 1975. Os militares na política - as mudanças de padrões na vida brasileira. Rio de Janeiro: Editora Artenova.

STM. Centro de Estudos Judiciários da Justiça Militar. 2013. Projeto de pesquisa institucional sobre condutas criminosas de maior incidência para a Justiça Militar da União. Relatório. Brasília.

Visconde de Taunay. 2008. A retirada da Laguna - episódio da Guerra do Paraguai. Brasília: Senado Federal. 


\section{NOTAS}

1. A respeito das intervenções militares no período 1946 a 1964, ver Martins Filho (2003).

2. Sobre crimes e infrações disciplinares na América Latina ver Castro y Bermeo (2008) e Bermeo, Castañeda e Castro (2010, 35-37).

3. Ver a esse respeito, CPDOC/FGV, Dossiê Justiça Militar. <http://cpdoc.fgv.br/justicamilitar>. Acesso em setembro de 2016.

4. Dados Do Boletim Estatístico de Pessoal de agosto de 2016. Acesso em outubro de 2016.

5. CNJ, dados do relatório do março de 2011. 


\section{A PERSISTENTE PRIMAZIA POLÍTICA DA CORPORAÇÃO MILITAR}

\section{RESUMO}

O trabalho divide-se em duas partes. Inicialmente abordaremos como a literatura clássica sobre os militares no Brasil abordou os vínculos da corporação com a sociedade e com o Estado, ou seja, aspectos cruciais das relações civil-militares. Em seguida faremos algumas considerações sobre a dinâmica atual dessas relações no Brasil tomando como foco a justiça militar. $\mathrm{O}$ ponto de vista defendido é o de que, apesar das mudanças políticas no país e das variações do enfoque teórico, as Forças Armadas continuam sendo uma instituição que mantém prerrogativas e ampla autonomia em seu formato institucional e em seu processo decisório.

Palavras-chave: Relações Civil-Militares; Forças Armadas; Justiça Militar; Prerrogativas Militares.

\section{ABSTRACT}

The work is divided into two parts. Initially, we discuss how the classical literature on the military in Brazil addressed the corporation's links with society and the State, that is, crucial aspects of civil-military relations. Then we will make some considerations about the current dynamics of these relations in Brazil taking as focus the military justice. Our point of view is that, despite the political changes in the country and changes in the theoretical approach, the Armed Forces continue to be an institution that holds wide powers and autonomy in its institutional form and in its decision-making process.

Keywords: Civil-Military Relations; Military; Military Justice; Military Prerogatives. 